\title{
Chillida-Leku, el esfuerzo de mantener un sueño, el compromiso de un legado
}

Laura Nogaledo Gómez | Dpto. Escultura e Historia de las Artes Plásticas, Universidad de Sevilla

URL de la contribución <www.iaph.es/revistaph/index.php/revistaph/article/view/4577>

Es el caso de Chillida-Leku, institución que en enero de 2011 se vio obligada a cerrar sus puertas. Esta espectacular museo recoge la obra de uno de los artistas más representativos y de gran transcendencia nacional e internacional, Eduardo Chillida (San Sebastián, 19242002). El museo fue inaugurado en el 2000, acto oficial al que acudieron los actuales reyes eméritos de España. La crisis económica y la falta de acuerdos de financiación entre la familia Chillida e instituciones públicas hicieron que el sueño de Eduardo Chillida permaneciese cerrado durante ocho años. Un centro de referencia nacional e internacional que tuvo que permanecer en suspenso.

\section{El sueño hecho realidad. Nacimiento de Chillida- Leku \\ Chillida-Leku no es un museo típico; fue pensado como una obra en sí misma por Eduardo Chillida. "Un día soñé una utopía: encontrar un espacio donde pudieran des- cansar mis esculturas y la gente caminara entre ellas como por un bosque"1.}

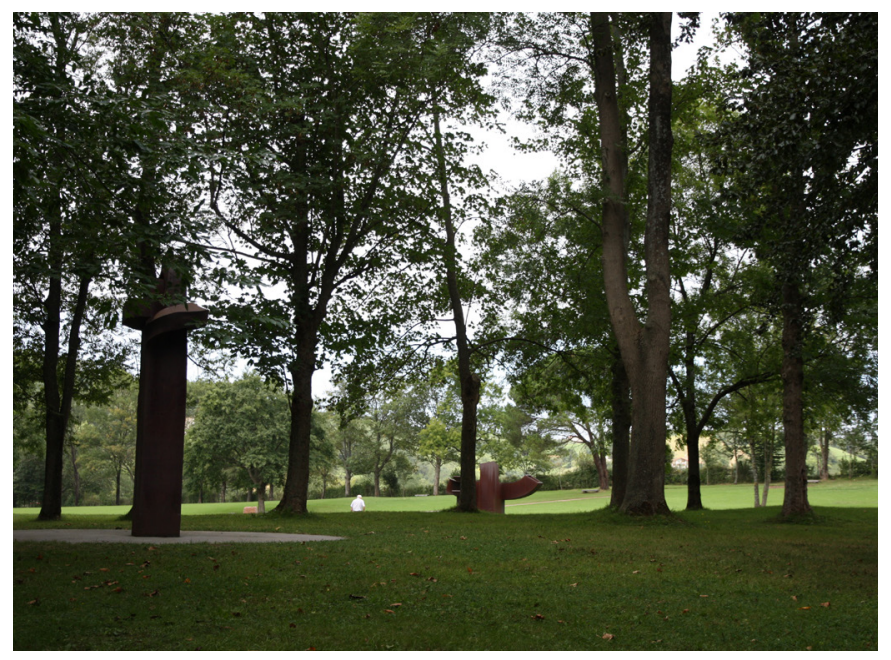

Chillida-Leku, nació de manera privada. El matrimonio Chillida, compuesto por Eduardo Chillida y Pilar Belzunce, adquirió el caserío Zabalaga, en Hernani, en 1984, y posteriormente las fincas que lo rodean. El caserío data de 1543 y es uno de los más antiguos que se conservan en Guipúzcoa, estando prácticamente en ruinas cuando lo adquirieron.

El proceso de restauración del caserío fue realizado por Eduardo Chillida, con la ayuda del arquitecto Joaquín Montero. "El método de trabajo lo impuso Eduardo y es su propio sistema de trabajo, avanzar paso a paso, parando si es preciso para reflexionar y con el único objetivo de la calidad y la obra bien hecha (...) Cuando oía hablar a Eduardo sobre escuchar los consejos que el propio edificio nos daba yo pensaba que era fruto de su forma poética de expresión, pero con el paso del tiempo me di cuenta de que efectivamente la casa nos ha dirigido de alguna forma" (EZQUIAGA, 2003: 27).

Chillida-Leku no fue pensado como un museo tradicional a modo de contenedor de la colección de obras de Eduardo Chillida. Es un proyecto que aglutina su producción y forma una obra en sí misma. Un lugar que recoge el legado de una vida dedicada al cuestionamiento del espacio, a través del metal, hormigón, piedra, barro o papel. Un emplazamiento que genera múltiples recorridos para el espectador que permite interactuar con las piezas, tocarlas, entrar en ellas, dialogar con ellas, sentirse parte de ellas. Donde el visitante busque su ritmo y camine libremente dialogando con un entorno perfectamente cuidado entre esculturas de toneladas de acero que encierran aromas y dialogan con el espacio.

El espacio gestionado principalmente por la familia Chillida, dirigido por su hijo Luis Chillida, cerró en 2011. 

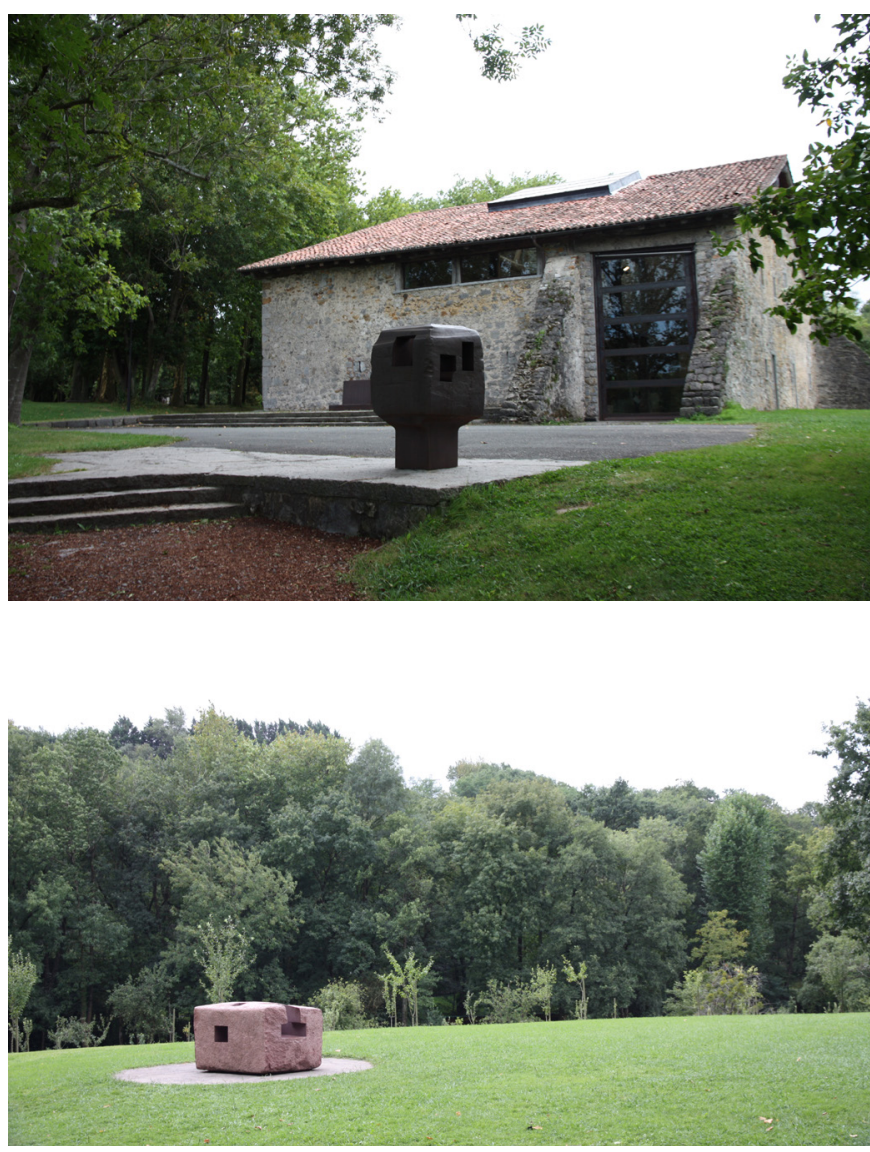

Chillida-Leku | fotos Laura Nogaledo

La crisis económica terminó con este sueño al no alcanzar la familia y las instituciones públicas un acuerdo de financiación, al no quedar salvaguardado el espíritu y el carácter monográfico del museo, en opinión de los herederos. "Ni con todo el dinero del mundo jamás hubiéramos cerrado un acuerdo si lo fundamental no se cumplía", declaraba Luis Chillida al diario ABC (REYERO, 2011).

Durante el cierre del museo, la familia ha permitido el acceso a la obra y documentación a investigadores y estudiosos de la figura de Eduardo Chillida.

\section{Reapertura de Chillida-Leku: el despertar del sueño} Han sido necesarios ocho años, pero afortunadamente en abril de 2019, Chillida-Leku reabrió sus puertas. La familia ha encontrado la manera de conjugar el espíritu del centro y la necesidad de financiación, combinando el ámbito privado, con la colaboración del sector público con diferentes administraciones del País Vasco, estableciendo un acuerdo con la galería suiza Hauser \& Wirth. "Ellos son unos especialistas en este tipo de trabajos. Nosotros somos una familia de artistas y hacemos las cosas lo mejor que podemos, pero no tenemos esa preparación. Ha sido fácil llegar a un acuerdo", afirmaba Luis Chillida al diario ABC (MATEOS, 2019).

La nueva etapa del museo estará dirigida por Mireia Massagué, exdirectora del Gaudí Exhibitoin Center.

Como conclusión señalar como la inclusión financiera del sector privado con la colaboración del público han permitido reabrir Chillida-Leku, salvaguardando la esencia del proyecto y el legado de Eduardo Chillida. Una colaboración desde diferentes sectores que convergen en un bien común.

\section{NOTAS}

1. Afirmación del propio escultor vasco, recogida en la página de inicio de la web de Chillida-Leku <https://www. museochillidaleku.com/museo/> [Consulta: 14/01/2020]

\section{BIBLIOGRAFÍA}

- EZQUiAgA, M. (2003) Museo Chillida-Leku: una utopía convertida en realidad. San Sebastián: Chillida-Leku, 2001

- REYERO, I. (2011) El museo Chillida-Leku echa el cierre definitivo. ABC [en línea] Cultura, 18 de marzo 2011, <https:// www.abc.es/cultura/arte/abci-chillida-201103180000_noticia. html> [Consulta: 14/01/2020]

- MATEOS, A. (2019) El museo Chillida Leku reabrirá en abril tras ocho años de cierre. $A B C$ [en línea] Cultura, 10 de enero de 2019 <https://www.abc.es/cultura/arte/abci-museo-chillidaleku-reabrira-abril-tras-ocho-anos-cierre-201901101124_ noticia.html> [Consulta: 14/01/2020] 